\title{
Early Enzyme Histochemical Changes Following Transection of Dorsal Spinal Funiculi
}

\author{
Uros Roessmann and Reinhard L. Friede ${ }^{1}$ \\ Mental Health Research Institute, University of Michigan, Ann Arbor, Michigan
}

Received January 8, 1965

\begin{abstract}
Histochemical studies of early changes of lactic dehydrogenase activity were done in transected fasc. gracilis and cuneatus of cats, to elucidate the significance of the proximo-distal increase in this enzyme normally found in the terminal portions of these tracts. A rapid and uniform loss of activity in the distal portion of transected tracts favors the concept that the gradient of enzyme activity in normal tracts results from a flow of axoplasm in the fasc. gracilis at a rate exceeding that of its catabolism, rather than an ability of the terminal portion of the axon to synthetize enzyme. Swellings and enzymatic changes in the stump of the transected axonal fibers suggest an early phase of redistribution of axoplasm in axonal stumps that occurs in both stumps, with a continued damming of axoplasm that occurs only in the proximal stumps. Transection of the sciatic nerve does not affect enzyme activity in the dorsal funiculi.
\end{abstract}

\section{Introduction}

Recent biochemical and histochemical studies have shown that levels of lactic dehydrogenase activity and activity of several other oxidative enzymes increase proximo-distally ${ }^{2}$ in axons in the terminal portion of the fasc. gracilis. Also, axon swellings with excessively increased enzyme activity are found in the terminal portion of the tract in normal animals. A similar, though smaller, proximo-distal increase of enzyme activity also occurs in the terminal portion of the fasc. cuneatus, and possibly in other tracts; however, the extent to which this phenomenon occurs in the fasc. gracilis appears to be unique (4).

The present experiments were performed to determine whether the high levels of activity in the terminal portion of these tracts result from local

1 This investigation was supported by a research fellowship 63900 and U.S. Public Health Grant B3250.

2 The distal end of the dorsal tracts is at their termination in the nuclei gracilis and cuneatus in the medulla oblongata; thus, proximo-distal in this text means caudocranial. 
production of enzymes in the axons, or to a rate of flow of enzyme-carrying axoplasm that exceeds the normal rate of its decomposition. The experiments also contribute to understanding the relations of normal axonal enzyme activity to the marked changes in activity that develop in the swollen stumps of severed axons. The accumulation of enzymes in the swollen proximal stumps of transected fibers was interpreted as damming of enzymes being transported via axonal flow (1). Other studies demonstrate, however, that accumulation of enzyme activity can also occur in the distal stumps of transected fibers; this phenomenon is transient and occurs only during the early phases after transection $(5,6,13)$. Moreover, increased enzyme activity was even found in both ends of an isolated segment of nerve $(2,7)$.

In the present study, we used lactic dehydrogenase only as a "marker" to indicate axoplasmic changes; previous studies have shown that the gradation of lactic dehydrogenase in the dorsal tracts, as demonstrated histochemically, corresponds exactly to the levels of activity found in biochemical assays of equivalent portions of homogenized tracts (4).

\section{Materials and Methods}

Fourteen adult female cats $(2-2.5 \mathrm{~kg})$ were used. Under barbiturate anesthesia the spinous processes of the second and third cervical vertebrae were removed, the dura was incised, and the cord was exposed. A 1-mm transverse incision was made near midline unilaterally in the dorsal funiculus. After surgery, two animals were quadriplegic, six showed some weakness in hind legs, and six were completely asymptomatic. Animals were killed 1-7 days after transection. Five additional animals, with the sciatic nerve transected on one side, were killed 2,7,14, 18, and 32 days later.

$\Lambda \mathrm{t}$ the necropsy, the spinal cord was removed and fixed for 24 hours in cold $10 \%$ neutral formalin. Longitudinal frozen sections $(30 \mu)$ were cut parallel to the course of the axons in the dorsal funiculi. The incubation medium was prepared immediately before use for each spinal cord and consisted of: $10 \mathrm{ml}$ sodium lactate, $0.5 \mathrm{M} ; 10 \mathrm{ml} \mathrm{NAD}, 0.01 \mathrm{M} ; 10 \mathrm{ml}$ potassium cyanide, $0.6 \mathrm{M} ; 10 \mathrm{ml}$ disodium dehydrogen EDTA, $6 \mathrm{mg} / \mathrm{ml} ; 30 \mathrm{ml}$ phosphate buffer, $0.1 \mathrm{M}, \mathrm{pH} 7.5$; and $30 \mathrm{ml}$ Nitro BT. Incubation was carried out for 1 hour in Erlenmeyer flasks in a water bath shaker at $38^{\circ} \mathrm{C}$ with constant agitation. The reaction was stopped by transferring the sections into $10 \%$ neutral formalin. Half of the sections were mounted in glycerin gel and the rest were dehydrated and mounted in Permount. Other 
sections were stained with routine histological methods, including chrome alum gallocyanin, Sudan black, and "Fettrot" stains.

\section{Results}

The site of tractotomy was slightly proximal to the level where the axons normally begin to show increased enzyme activity in the fasc. gracilis. The results were the same in fasc. gracilis and cuneatus, although the various changes were much more pronounced in the fasc. gracilis because of its normally higher levels of enzymatic activity. Within 1 day, axonal swelling and increased enzyme activity occurred in both proximal and distal stumps. From the second day on, axonal enzyme activity decreased rapidly in the distal stumps and throughout the disconnected portion of the axon. During the same period, enzyme activity increased progressively in the proximal stumps and there was no loss of enzyme activity in any part of the proximal portion of the fibers (Table 1).

Early Swellings in Both Stumps. One day after transection, swollen axons with increased enzyme activity occurred almost equally in both stumps of

TABLE 1

Location and Intensity of Enzymatic Activity Following Transection of Dorsal Funiculi

\begin{tabular}{|c|c|c|c|c|c|c|c|}
\hline \multirow[b]{2}{*}{ Cat No. } & \multirow{2}{*}{$\begin{array}{l}\text { Days } \\
\text { surv. }\end{array}$} & \multirow{2}{*}{$\begin{array}{c}\text { Fasc. } \\
\text { transect. }{ }^{a}\end{array}$} & \multicolumn{2}{|c|}{$\begin{array}{c}\text { Activity in } \\
\text { axonal stumps }\end{array}$} & \multicolumn{2}{|c|}{$\begin{array}{l}\text { Activity in } \\
\text { axons }\end{array}$} & \multirow{2}{*}{$\begin{array}{l}\text { Cell. resp. } \\
\text { in dist. } \\
\text { segment }\end{array}$} \\
\hline & & & Prox. & Dist. & Prox. & Dist. & \\
\hline 329 & 1 & $\mathrm{Cu}$. & ++++ & $++t$ & 0 & 0 & 0 \\
\hline 333 & 1 & $\mathrm{Cu}$. & $+t+t$ & ++ & 0 & 0 & 0 \\
\hline 342 & 1 & Cu. \& Gr. & $++t+$ & $+t+$ & 0 & 0 & 0 \\
\hline 344 & 1 & Cu. \& Gr. & ++++ & +++ & 0 & 0 & 0 \\
\hline 341 & 2 & $\mathrm{Gr}$ & ++++ & ++ & 0 & - & 0 \\
\hline 343 & 2 & Gr. & $+t+1$ & ++ & 0 & 0 & 0 \\
\hline 340 & 3 & Cu. \& Gr. & ++++ & ++ & 0 & -- & 0 \\
\hline 354 & 4 & Gr. & $+t+t$ & + & 0 & -- & 0 \\
\hline 356 & 4 & Gr. & ++++ & + & 0 & -- & 0 \\
\hline 335 & 6 & Gr. & ++++ & + & 0 & -- & 0 \\
\hline 353 & 6 & $\mathrm{Cu}$ \& Gr. & ++++ & + & 0 & -- & 0 \\
\hline 334 & 7 & $\mathrm{Cu}$. & ++++ & + & 0 & -- & 0 \\
\hline 359 & 7 & Gr. & ++++ & + & 0 & -- & $?$ \\
\hline 349 & 7 & $\mathrm{Cu}$. & ++++ & + & 0 & -- & 0 \\
\hline
\end{tabular}

${ }^{a} \mathrm{Cu} .=$ fasc. cuneatus; $\mathrm{Gr} .=$ fasc. gracilis.

${ }^{b}$ Degrees of activity: $++++=$ intense; $+++=$ marked; $++=$ moderate; $t=$ minimal (few drops) $; 0=$ unchanged; ? = questionable change $;-=$ decreased; $-\cdots=$ complete loss. 
the severed fibers (Fig. 1). From day 1 on, however, a difference between the distal and proximal stumps developed. While the swelling and increase of enzyme activity increased with time in the proximal stumps (see below), there was no increase beyond the second day in the distal stumps, where the axons disintegrated to small droplets and spheres of axoplasm in which enzyme activity decreased from the second to fourth day and were rarely seen by the seventh day.

Loss of Enzyme Activity From the Distal Segment. The distal, disconnected segment showed a decrease in enzyme activity 48 hours after transection (Fig. 2) and complete lack of enzyme activity from the third day on (Fig. 3). ${ }^{3}$ The decrease in enzyme activity was simultaneous throughout the segment; there was no indication of a gradation of enzyme activity in the most distal portion of the segment. The bundles of transected fibers contrasted sharply with the intact fibers throughout the length of the tract.

Persistent Swellings in the Proximal Stumps. The swellings in the proximal stumps were characteristically club-shaped and tended to grow larger, and bulge, throughout the 7 days of the experiment and enzyme activity increased in them progressively. Moreover, a proximo-distal increase of enzyme activity, similar to that normally seen in the terminal portion of the tract, was built-up proximal to the transection (Fig. 3), increasing in length from $0.5 \mathrm{~mm}$ on the first day to $2 \mathrm{~mm}$ on the fourth day. Further proximal, the transected axons did not appear different from the intact ones.

Neuroglial Response. No increase in cell population was noted either in proximal or distal tract segments, except that in one animal, killed on the seventh day, a minimal increase in cell number seemed to occur in the distal portion of the transected tracts. In the distal segment, the persistent enzyme activity in neuroglia cells was in a marked contrast to its complete disappearance from the axons after the second day. Frozen sections showed no free fat in preparations up to and including those made on the seventh day.

Other Changes. In addition to the axonal swellings at the site of transection, a few swollen axons were occasionally obscrved in other spinal tracts. Probably these were the result of accidental trauma to the spinal cord during surgery.

Transection of the Sciatic Nerve. No changes of enzyme activity were detected in fiber bundles within the dorsal funiculi of five cats which were killed 2 to 32 days after transection of the sciatic nerve.

3 Coincident with the decrease in enzyme activity, the club-shaped swollen endings in the axonal stumps began to disintegrate. 


\section{Discussion}

In a previous study (4) two hypotheses were considered regarding the cause of the proximal-distal increase of axonal enzyme activity and the development of axonal swellings in the fasc. gracilis of normal animals. (i) The uneven distribution of axonal enzyme activity may represent an accumulation of enzymically active axoplasm resulting from a proximal to distal convection that exceeded the rate of utilization or decay of the axoplasm, or both. (ii) Enzyme synthesis may occur in the presynaptic portion of the axons and result in excessive accumulation of axoplasm there. The results of the present experiment support the axoplasmic flow hypothesis and do not seem compatible with the hypothesis of local synthesis of enzyme. If the terminal portion of an axon had the capacity to produce enzyme activity, so that the normal gradation of enzyme activity observed in the fiber would be the result of local enzyme formation, then it would be improbable that the distal, disconnected segment would lose its enzyme activity so quickly after transection. Also, one would not expect the loss to occur simultaneously along the entire segment.

Several investigators $(4,9-11)$ reported swollen axons in the distal portion of the fasc. gracilis in normal animals and human beings. Sung (11) showed that the "normally" occurring axon swellings in human gracile and cuneate nuclei first appear in the third decade of life and increase in number with advancing age. The development of swollen axons ("dystrophic"

FIg. 1. Axon swellings with increased activity of lactic dehydrogenase appear at 24 hours after surgery in both the proximal and the distal stumps of the transected fibers. There are no evident changes of enzyme activity in the axons at some distance from the stumps. Longitudinal section through the tractotomy site; caudal is to the left. $65 \times$.

FIr. 2. Three days after unilateral transection of the fasc. gracilis, lactic dehydrogenase is decreased in the transected tract (gr. b). The nontransected tract shows the intense reaction which is normally found in the terminal portion of the fasc. gracilis (gr. a); the fasc. cuneatus (cu.) shows much weaker activity. Longitudinal section through the cervical cord cut in a plane through the insertion of the dorsal rootlets on both sides. The field demonstrates the tracts several segments above the tractotomy site; caudal is to the right. $50 \times$.

FIg. 3. Four days after transection there is no lactic dehydrogenase activity in the distal axonal segments, while a build-up of enzyme activity developed proximally to the transection. The lower (uncut) fasc. gracilis demonstrates the normal proximodistal (right to left) increase in enzyme activity. Note that a small bundle (lowermost) of the upper tract was not cut; normal enzyme activity in this bundle contrasts sharply with the loss of activity in the severed fibers; caudal is to the right. $40 \times$. 


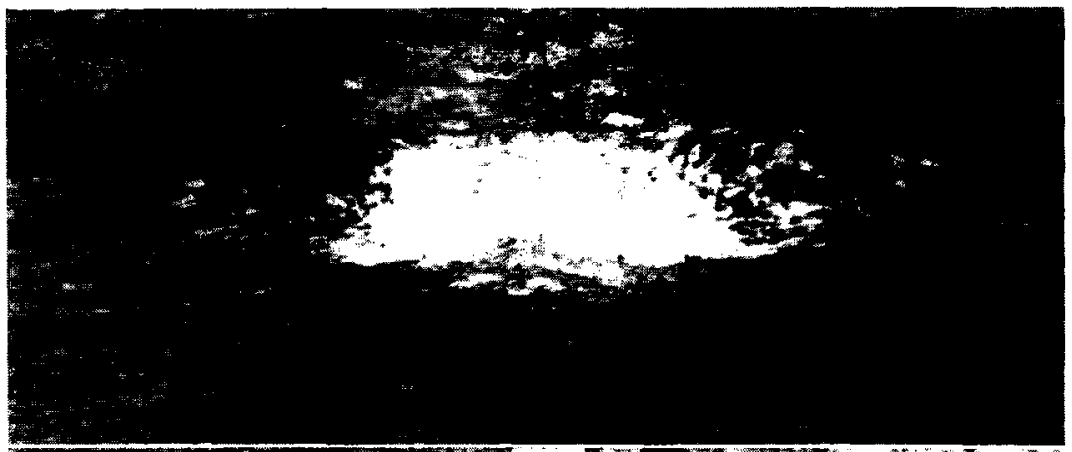

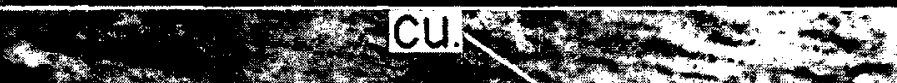
6h

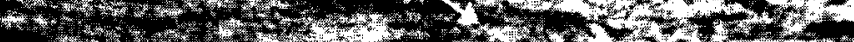

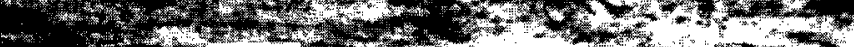

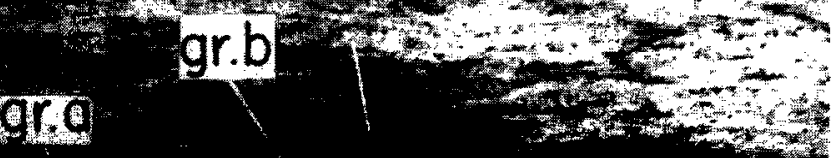
gra

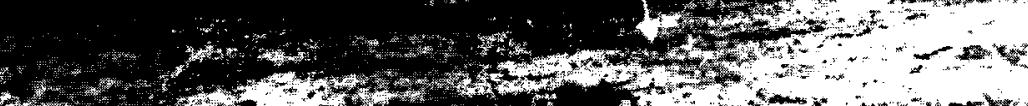

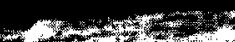

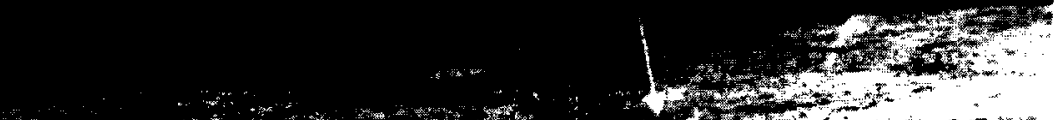

wat 1 or

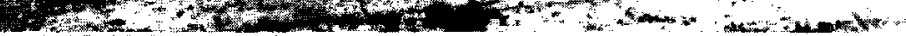

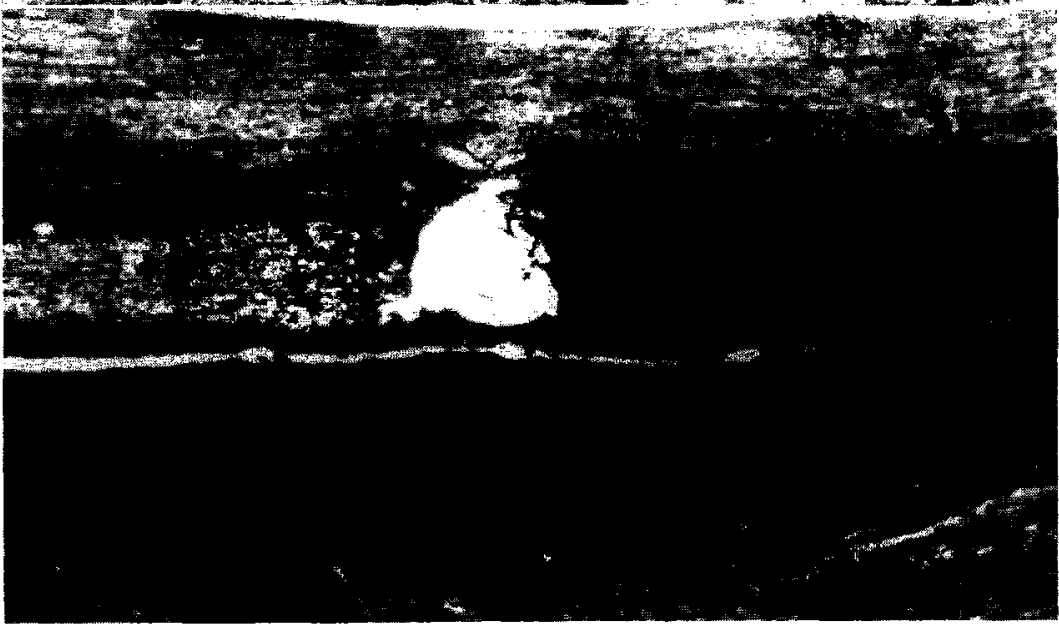


axons, "Stachelkugeln," "retraction bulbs") is most logically explained as a local accumulation of axoplasm due to an interference with the proximaldistal flow. When a fiber is physically cut, crushed or pinched or interrupted by an infarct, the etiology of the swelling seems clear. However, we can only speculate as to what factors initiate the stemming of axoplasmic flow along the axon with aging or in various other conditions, such as infantile neuroaxonal dystrophy, Hallervorden-Spatz disease, vitamin E deficiency, or Kuru. It could be due to a redundant flow of axoplasm or to an interference with the rate of utilization of axoplasmic contents such as a loss or deficiency of catabolizing enzymes at or near the synaptic end of the axon.

The pattern of enzyme activity in the transected axonal stumps also deserves discussion. For the first day following transection increased enzyme activity (damming) is present in both the proximal and distal stumps. These early changes in both stumps occur even at both ends of an isolated segment of nerves as quoted above. Lubinska, et al. (8) demonstrated that such changes reflect a redistribution of enzyme activity within the segment, rather than a reactive formation of enzyme at the stumps. An increase of cholinesterase activity at both stumps of isolated segments of nerve was correlated with a decrease in the central portion, while the total activity of the isolated segment had not changed. A similar redistribution of activity has been found for oxidative enzymes in both stumps of isolated nerve segments (2). Local forces evidently account for these early changes; merhanisms that were proposed are the tendency of axoplasm to settle at blind ends (8), or a shifting of axoplasm due to injury currents in the stumps (3). Perhaps this early accumulation of enzyme activity is identical with the redistribution and accumulation of axoplasmic mitochondria in early phases of Wallerian degeneration (12).

In conclusion, the changes in enzymatic activity in the stump of a transected fiber probably are the complex result of several interacting processes. The early changes in both stumps may be the result of a redistribution of axoplasm similar to that demonstrated by Lubinska, et al. $(4,8)$ in isolated nerve segments. The continuing accumulation of axoplasm in the proximal stumps is more likely the result of damming of axonal flow.

No enzymatic changes were found in fibers, or fiber bundles within the dorsal tracts following sciatic nerve transection, although this procedure removes the afferent segments of those neurons from which ascending fibers in the dorsal tracts arise. We have not found any previous references to this remarkable lack of reactivity of the dorsal tracts to transections of peripheral nerves. 


\section{References}

1. Friede, R. L. 1959. Transport of oxidative enzymes in nerve fibers. A histochemical investigation of the regenerative cycle in neurons. Exptl. Neurol. 1: 441-466.

2. FrIEDE, R. L. 1964a. Electrophoretic production of "reactive" axon swellings in vitro and their histochemical properties. Acta Neuropathol. 3: 217-228.

3. FrIEde, R. L. 1964b. Axon swellings produced in vivo in isolated segments of nerves. Acta Neuropathol. 3: 229-237.

4. Friede, R. L., AND M. KnolLer. 1964. Proximo-distal increase of enzymatic activity in the dorsal spinal tracts. $J$. Neurochem. 11: 679-686.

5. KreUtzBerg, G. 1963. Lukalisierter Oxydureduktasenanstieg bei der Wallerschen Degeneration des peripheren Nerven. Naturwissenschaften 50: 96.

6. KreutzberG, G., and W. Wechsler. 1963. Histochemische Untersuchungen oxydativer Enzyme am regenerierenden Nervus ischiadicus der Ratte. Acta Neuropathol. 2: 349-361.

7. Lubinska, L., S. Niemierko, B. Oderfeld, L. Szwarc, and J. Zelena. 1963. Bidirectional movements of axoplasm in peripheral nerve fibers. Acta Biol. Exptl. Polish Acad. Sci. 23: 239-247.

8. Lubinska, L., S. Niemterko, B. Oderfeld-Nowak, and L. Szwarc. 1964. Behaviour of acetylcholinesterase in isolated nerve segments. J. Neurochem. 11: 493-503.

9. Newberne, J. W., V. B. Robinson, L. Estill, and D. C. Brinkman. 1960. Granular structures in brains of apparently normal dogs. Am.J. Vet. Res. 21: 782-786.

10. Pentschew, A., And K. Schwarz. 1962. Systemic axonal dystrophy in vitamin E deficient adult rats. Acta Neurophatol. 1: 313-334.

11. Suvg, J. H. 1964. Neuroaxonal dystrophy in mucoviscidosis. J. Neuropath. Exptl. Neurol. 23: 567-583.

12. Webster, H. deF. 1962. Transient, focal accumulation of axonal mitochondria during the early stages of Wallerian degeneration. J. Cell Biol. 12: 361-383.

13. ZeLENA, J., AND L. LUBinsKA. 1962. Early changes of acetylcholinesterase activity near the lesion in crushed nerves. Physiol. Bohemoslov. 11: 261-268. 